\title{
Aspectos clínicos, ocorrência e tratamento da artrogripose cárpica congênita em bezerros em uma população de 27300 bovinos (1984-2004)
}

\author{
Clinical aspects, ocurrence and treatment of congenital carpic \\ arthrogriposis in calf in a population of 27,300 bovines (1984-2004) \\ Luiz Antônio Franco da Silva', Leandro Guimarães Franco ${ }^{2}$, Duvaldo Eurides ${ }^{3}$, Olízio Claudino da Silva', \\ Marco Augusto Machado Silva ${ }^{2}$, Adilson Donizeti Damasceno', Rosângela de Oliveira Alves', Maria \\ Ivete de Moura ${ }^{4}$, Andressa Mendes Garcia ${ }^{2}$ \& Bruno Rodrigues Trindade ${ }^{5}$
}

\begin{abstract}
RESUMO
A artrogripose é uma enfermidade congênita caracterizada por rigidez das articulações, em flexão, dos membros torácicos e pélvicos, que acomete principalmente bovinos e eqüinos. Avaliou-se o tratamento cirúrgico associado a fixação articular externa com tubos de policloreto de vinila (PVC) ou muleta de Thomas modificada, em bezerros portadores de artrogripose cárpica congênita. $\mathrm{O}$ estudo desenvolveu-se em 18 propriedades rurais, utilizando 21 bezerros portadores dessa enfermidade, distribuídos em três grupos (GI, GII e GIII) de sete animais. O GI foi constituído de animais portadores da enfermidade em grau leve e os GII e GIII, por bovinos gravemente afetados. Em todos os animais, realizou-se na região metacarpiana, tenotomia nos tendões dos músculos flexores digitais, superficial e profundo e nos bovinos do GII e do GIII, desfez-se a anquilose articular. Nos bezerros provenientes do GI e GII, promoveu-se a fixação externa da articulação cárpica utilizando a muleta de Thomas modificada e nos do GIII, um equipamento confeccionado a partir de tubos de PVC. Os tratamentos instituídos não resultaram na cura total de todos os bovinos, porém foi suficiente para permitir que os animais apoiassem a extremidade distal do membro ao solo e se locomovessem, mesmo claudicando. Tanto a Muleta de Thomas modificada como o tubo de PVC auxiliaram no restabelecimento dos movimentos da articulação cárpica.
\end{abstract}

Descritores: artrogripose, bezerros, ocorrência, diagnóstico, tratamento.

\section{ABSTRACT}

The arthrogryposis is a congenital disease characterized by ankylosis of articulation, flexion of the thoracic and pelvic limbs, that mainly bovines and equines. It was evaluated the surgical treatment associated to articular external fixation with vinile polichlorate (PVC) or Thomas splint modified, in calves owners of congenital carpic arthrogryposis. The study was developed in 18 farms and it was used 21 calves owners of this infirmity, distributed in three groups (GI, GII and GIII) of seven animas. The GI was constituted by animals with a soft score of the infirmity and the GII and GIII, by bovines hardly affected. On all the animals, it was done the tenotomy of the superficial and deep digital flexor tendon on the metacarpian region and on the bovines from GII and GIII, it was undone the articular anchilosis. On the calves from GI and GII, it was done the external fixation of the carpic articulation using the Thomas splint modified and on the ones from GIII, an equipment made of PVC tubes. The treatments preconized did not result on the complete cure of all bovines, although it was sufficient to allow the animals to step the distal extremity of the limb on the floor and to walk, even claudicating. As the Thomas splint modified as the PVC tube were helpful on the reestablishment of the movements of the carpic articulation.

Key words: arthrogryposis, calves, occurrence, diagnostic, treatment. 


\section{INTRODUÇÃO}

A artrogripose é uma enfermidade congênita caracterizada por rigidez das articulações, em flexão, dos membros torácicos e pélvicos, que acomete principalmente bovinos e eqüinos $[12,15]$. Tal condição clínica é atribuída a um defeito primário dos músculos (displasia ou amioplasia) ou atrofia neurogênica resultante da ausência de neurônios motores na medula espinhal ou da desmielinização dos nervos motores, podendo haver o envolvimento de características recessivas hereditárias na gênese da doença, infecções virais (vírus Akabane; vírus da língua azul; vírus da moléstia das fronteiras) e ingestão de vegetais teratogênicos (vegetal do tremoço) durante a gestação [1,2,5,8-12,18,21].

Os animais com artrogripose geralmente nascem de partos distócicos, apresentam dificuldade de se manterem em posição quadrupedal. A enfermidade pode ocorrer bilateralmente e, raramente, apresenta-se como causa primária e sim associada a sinais clínicos de comprometimento do sistema nervoso central.

Apesar da doença ser relativamente freqüente em bezerros neonatos, corroborado pelo pequeno número de trabalhos científicos publicados, poucas informações sobre o assunto foram obtidas na literatura consul- tada, especialmente sobre a ocorrência e o emprego de alternativas viáveis para o tratamento da moléstia.

O objetivo do estudo foi estabelecer a ocorrência, avaliar os aspectos clínicos e a eficiência do tratamento cirúrgico associado a fixação articular externa, empregando tubos de policloreto de vinila (PVC) e muleta de Thomas modificada na imobilização do membro acometido por artrogripose cárpica congênita em bezerros, sem sinais clínicos de comprometimento do sistema nervoso central.

\section{MATERIAIS E MÉTODOS}

O estudo foi realizado em 18 propriedades rurais do Estado de Goiás, no período compreendido entre 1984 e 2004, utilizando 21 bezerros recém-nascidos portadores de artrogripose cárpica congênita, distribuídos entre nove raças diferentes (Tabela 1), oriundos de um rebanho de 27300 animais. Desses, 12.530 eram fêmeas, sendo 2.118 na faixa etária entre zero e um ano, 4.070 entre um e três anos e 6.342 com idade superior a três anos. Dos 14.770 machos, 3500 encontravam-se na faixa etária entre zero e um ano, 11.050 entre um e três anos e 220 acima de três anos. O estudo realizou-se a partir da casuística atendida no período de vinte anos,

Tabela 1. Distribuição do número total de bezerros, machos e fêmeas, na faixa etária entre zero e um ano, de acordo com a raça, presença da artrogripose cárpica, a idade em meses, em diferentes propriedades rurais no período compreendido entre 1984 e 2004.

\begin{tabular}{|c|c|c|c|c|c|c|c|c|}
\hline \multirow[t]{2}{*}{ Raça } & \multirow{2}{*}{$\begin{array}{l}\text { Bezerros com } \\
\text { artrogripose cárpica } \\
\text { congênita }\end{array}$} & \multicolumn{3}{|c|}{ Idade em meses } & \multicolumn{2}{|c|}{ Sexo } & \multicolumn{2}{|c|}{$\begin{array}{c}\text { Total de bezerros } \\
\text { entre zero e } 12 \\
\text { meses }\end{array}$} \\
\hline & & $0-4$ & $4-8$ & $8-12$ & $M^{*}$ & $\mathrm{~F}^{\star *}$ & M & $\mathrm{F}$ \\
\hline Blonde D'Aquitaine & 1 & 1 & - & - & - & 1 & 120 & 53 \\
\hline Charolesa & 1 & - & 1 & - & 1 & - & 105 & 13 \\
\hline Gir & 2 & 1 & 1 & - & 1 & 1 & 147 & 41 \\
\hline Girolando & 3 & 2 & 1 & - & 1 & 2 & 439 & 235 \\
\hline Guzerá & 1 & 1 & - & - & 1 & - & 241 & 58 \\
\hline Holandesa & 1 & 1 & - & - & 1 & - & 120 & 49 \\
\hline Indubrasil & 1 & 1 & - & - & 1 & - & 60 & 18 \\
\hline Limosin & 1 & 1 & - & - & 1 & - & 73 & 60 \\
\hline Nelore & 7 & 5 & 1 & 1 & 6 & 1 & 1767 & 1402 \\
\hline Santa-Gertrudis & 1 & 1 & - & - & 1 & - & 166 & 80 \\
\hline Simental & 2 & 2 & - & - & 1 & 1 & 262 & 109 \\
\hline Total & 21 & 16 & 4 & 1 & 15 & 6 & 3500 & 2118 \\
\hline
\end{tabular}


sendo somente considerados os dados referentes aos rebanhos das propriedades onde ocorreram os atendimentos.

Os animais foram alocados independentemente da raça, em três grupos (GI, GII e GIII) contendo sete bovinos cada, de acordo com o tratamento recebido. Convencionou-se que os casos considerados de menor gravidade, com flexão parcial da articulação cárpica, seriam alocados no GI e os casos com flexão cárpica rígida, nos GII e GIII.

O pré-operatório constou de jejum completo de 12 horas, tranquiilização com cloridrato de xilazina na dose de 0,05 a $0,1 \mathrm{mg} / \mathrm{kg}$ de peso corporal, contenção em decúbito lateral, tricotomia das regiões metacarpianas dos animais de todos os grupos e, anterior e posterior à articulação cárpica, nos animais dos GII e GIII, seguida da antissepsia com solução de iodophor na concentração 1:250. A anestesia local utilizando cloridrato de lidocaína a $2 \%$ foi praticada a aproximadamente cinco centímetros cranial à articulação cárpica, empregando-se aproximadamente $40 \mathrm{~mL}$ do fármaco por animal.

Após incisão de pele, realizou-se a tenotomia nos tendões dos músculos flexores digitais, superficial e profundo na região metacarpiana nos bovinos dos GI, GII e GIII e nos animais alocados nos GII e GIII, desfez-se a anquilose articular utilizando formão cirúrgico e folha de Salvia. Na dermorrafia, em todos os bovinos, empregou-se fio de algodão 2-0 em sutura padrão simples. Nos bezerros provenientes do GI e GII, promoveu-se a imobilização externa da articulação cárpica utilizando a muleta de Thomas modificada [17], adaptada para a espécie bovina. A modificação do equipamento constou da transformação do aro metálico para a forma de sela, permitindo também sua fixação no membro contralateral. Nos recém-nascidos alocados no GIII, procedeu-se a fixação externa da articulação com um equipamento confeccionado a partir de tubos de policloreto de vinila, tomando-se o cuidado de deixar abertura compatível com as dimensões das feridas cirúrgicas, para facilitar os curativos. As regiões do membro onde ocorreu contato com o tubo, foram protegidas com algodão ortopédico e ataduras elásticas, sendo o ajuste do seu diâmetro realizado de acordo com o grau de extensão do membro e facilitado pela abertura longitudinal praticada no PVC.

$\mathrm{O}$ tubo de PVC foi fixado com arame na pinça do casco e com atadura elástica na região axilar do membro contralateral, obtendo-se um formato semelhante à sela da Muleta modificada (Figura 1). Ambos os equipamentos foram removidos entre 30 e 45 dias do pós-operatório, considerando sempre a cicatrização clínica da ferida cirúrgica e a capacidade de apoio do membro tratado ao solo.

No pós-operatório, preconizou-se, via intramuscular, uma associação de penicilinas, na dose de $20.000 \mathrm{UI} / \mathrm{kg}$ de peso corporal a cada 48 horas até completar cinco aplicações e, na ferida cirúrgica, aplicação diária de pomada contendo o mesmo princípio ativo até cicatrização clínica completa. Os pontos empregados na dermorrafia foram removidos ao décimo segundo dia do pós-operatório e os animais avaliados no momento da remoção da imobilização externa, classificando-se o resultado como recuperação parcial, total ou não recuperados. Para a realização da comparação da ocorrência da artrogripose cárpica entre os sexos, dividiu-se o número total de bezerros na faixa etária entre zero e um ano, tendo como referência para a propriedade o dia do atendimento do animal e a taxa de natalidade de bezerros nos últimos doze meses. $\mathrm{Na}$ comparação da ocorrência entre raças, agrupou-se
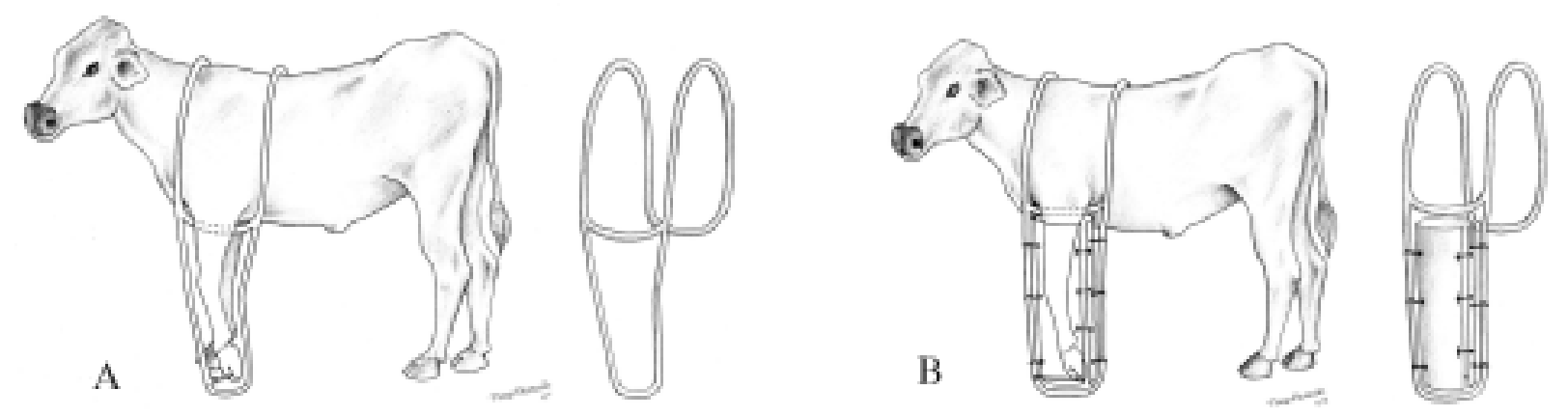

Figura 1. (A) Esquema ilustrativo da utilização da Muleta de Thomas Modificada como método auxiliar de fixação externa no membro torácico dos bovinos; (B) Esquema ilustrativo da utilização do tubo de PVC como método auxiliar de fixação externa no membro torácico dos bovinos. 
os animais em duas categorias, sendo as raças Holandesa, Girolando e Gir Leiteiro contidas no grupo de Leite/ Dupla aptidão e as outras raças constituindo o grupo denominado Corte. Na avaliação estatística entre os grupos de raças e entre sexos utilizou-se o teste de Quiquadrado com correção para a continuidade ao nível de significância (NS) de 5\% [3]. A comparação estatística da eficiência da Muleta de Thomas modificada entre o GI e o GII foi realizada pelo teste exato de Fischer, adotando-se NS de 5\% [3]. O mesmo teste foi empregado para comparar a eficiência entre os tratamentos adotados para os animais do GII e os pertencentes ao GIII.

\section{RESULTADOS}

Analisando o resultado dos exames clínicos de todos os animais atendidos com artrogripose cárpica congênita, não foi possível identificar comprometimento do sistema nervoso central.

Embora os movimentos da articulação comprometida apresentassem diminuídos e houvesse indícios de que os músculos e tendões possuíam dimensões inferiores às de um bezerro neonato saudável, não foram observados achados clínicos de processo inflamatório no local. No estudo realizado, não se observou qualquer alteração clínica como hidrocefalia, palatosquise, escoliose e disrafia espinhal.

Observou-se que $15(71,44 \%)$ dos 21 animais pertenciam a raças especializadas na produção de carne, cinco $(23,80 \%)$ a raças mistas e apenas um animal $(4,76 \%)$ pertencia a raças de aptidão leiteira, não se observando diferença estatística entre a frequiência de ocorrência de artrogripose cárpica congênita entre as diferentes raças, contudo houve uma tendência dos animais das raças de aptidão para corte apresentarem maior ocorrência do problema (Tabela 2).

Analisando apenas a evolução clínica do processo, verificou-se que no GI, um bovino da raça Blonde D'Aquitaine e um Girolando recuperaram-se parcialmente. Em dois da raça Nelore, um Guzerá, um Gir, um Santa Gertrudes a recuperação foi total. No GII, um bezerro da raça Holandesa, dois Nelore e um Indubrasil apresentaram recuperação parcial e apenas um da raça Nelore recuperou-se totalmente. Um bezerro da raça Girolando e um Simental não se recuperaram, sendo, portanto, sacrificados. Quanto aos animais pertencentes ao GIII, em um da raça Charolesa, um Gir, um Simental, um Girolando e um Nelore, a recuperação foi parcial. Em um bovino da raça Nelore a recuperação foi total e um da raça Limosin não se recuperou, sendo necessário realizar seu sacrifício.

A recuperação dos casos pertencentes ao GI, cujo comprometimento da flexão cárpica era parcial, foi completa em cinco bezerros $(71,43 \%)$ e parcialmente em dois animais $(28,57 \%)$.

Observando a ocorrência do problema, verificouse que $71,44 \%$ dos bovinos acometidos eram machos e apenas $28,56 \%$ eram fêmeas (Tabela 3 ).

Independente do grupo ao qual pertenciam, os tratamentos instituídos não resultaram na cura total de todos os bovinos, porém permitiu que os animais apoiassem a extremidade distal do membro ao solo e se locomovessem, mesmo claudicando.

Empregando-se o teste de Fischer, quando comparou-se a recuperação dos animais que constituíram o GI e os que compuseram o GII, não se observou diferença significativa (Tabela 4). No entanto, todos os animais alocados do GI apresentaram algum sinal de recuperação.
Tabela 2. Teste de Qui-quadrado com correção para a continuidade para a comparação da ocorrência da artrogripose cárpica congênita entre animais pertencentes a raças de aptidão para corte e raças de leite/dupla aptidão, entre parênteses freqüência esperada.

\begin{tabular}{lccc}
\hline \multirow{2}{*}{ Artrogripose } & \multicolumn{2}{c}{ Aptidão } & Total \\
\cline { 2 - 3 } & Corte & Leite/dupla & \\
\hline Ausente & $4572(4570)$ & $1025(1027)$ & 5597 \\
Presente & $15(17)$ & $6(4)$ & 21 \\
\hline Total & 4587 & 1031 & 5618 \\
\hline$\chi^{2}=10,84 ; \mathrm{p}<0,05$. & & &
\end{tabular}

Tabela 3. Comparação da ocorrência de artrogripose cárpica congênita entre animais do sexo masculino e feminino; entre parênteses, freqüência esperada, utilizando-se o teste de Qui-quadrado com correção para a continuidade NS 5\%.

\begin{tabular}{lccc}
\hline \multirow{2}{*}{ Artrogripose } & \multicolumn{2}{c}{ Sexo } & Total \\
\cline { 2 - 4 } & Masculino & Feminino & \\
\hline Ausente & $3485(3486)$ & $2112(2110)$ & 5597 \\
Presente & $15(13)$ & $6(8)$ & 21 \\
\hline Total & 3500 & 2118 & 5618 \\
\hline$\chi^{2}=0,41 ; \mathrm{p}<0,05$. & & &
\end{tabular}


Tabela 4. Comparação da eficiência da utilização da Muleta de Thomas modificada na recuperação da artrogripose cárpica congênita, entre bovinos levemente afetados alocados no grupo 1 (G1) e bovinos apresentando grau mais avançado da doença, grupo 2 (G2), utilizando-se o teste exato de Fischer, adotando-se um NS de $5 \%$.

\begin{tabular}{|c|c|c|}
\hline Grupos & $\mathrm{NR}^{*}$ & $\mathbf{R}(\mathrm{T} / \mathrm{P})^{\star *}$ \\
\hline GI & 0 & 7 \\
\hline GII & 2 & 5 \\
\hline
\end{tabular}

A eficiência do tratamento cirúrgico associado à utilização da Muleta de Thomas como método auxiliar de fixação externa ficou evidente ao analisar a evolução clínica dos casos mais graves, que aparentemente seriam de difícil recuperação, uma vez que dos sete animais atendidos e alocados no GII, cinco apresentaram recuperação parcial dos movimentos da articulação cárpica. Tanto nesse grupo, quanto no GIII, os casos que se recuperaram parcialmente apresentaram limitações em seus movimentos durante a locomoção. No GIII, em cinco bezerros $(23,81 \%)$ ocorreu consolidação das estruturas articulares, com nítido aumento da região articular abordada. Em dois animais $(9,52 \%)$ após a remoção da fixação externa, possivelmente pela tenotomia, o apoio do membro ao solo passou a ser efetuado, utilizando as extremidades metacarpianas, falange proximal e talões.

Um animal pertencente ao GIII $(4,76 \%)$ e dois $(9,52 \%)$ do GII, devido à artrite supurativa com presença de fístula, dificuldade para se locomover e apresentarem emagrecimento progressivo, foram sacrificados aos 60 dias do pós-operatório.

Não houve diferença significativa entre os métodos de fixação externa empregados no tratamento dos animais que compuseram os GII e GIII (Tabela 5), mas os números indicam que o método de fixação externa com tubo PVC resultou em maior número de recuperação, parcial ou total, embora ambos os tratamentos tenham apresentado resposta positiva quanto ao restabelecimento dos animais.

\section{DISCUSSÃO}

Alguns autores $[1,18]$ afirmam que freqüientemente a enfermidade apresenta-se associada a lesão primária do sistema nervoso central, caracterizando-se por atrofia muscular em consequiência da ausência de neu-
Tabela 5. Comparação da eficiência dos tratamentos auxiliares de fixação externa adotados na recuperação da artrogripose cárpica congênita entre animais do grupo 2 (GII), Muleta de Thomas modificada, e grupo 3 (GIII), Tubo de PVC, utilizando-se o teste exato de Fischer, adotando-se um NS de $5 \%$.

\begin{tabular}{ccc}
\hline Grupos & NR $^{*}$ & $\mathbf{R}(\mathbf{T} / \mathbf{P})^{* *}$ \\
\hline GII & 2 & 5 \\
GIII & 1 & 6 \\
\hline $\mathrm{p}=0,5 ; *$ Animais não recuperados; **animais recuperados (total ou \\
parcialmente).
\end{tabular}

rônios nos cornos ventrais da medula ou desmielinização dos nervos motores, contrariando os achados deste estudo. A limitação dos movimentos da articulação cárpica mantendo-a flexionada durante a gestação, pode ter comprometido seus movimentos de diartrose, necessários a locomoção normal do animal, conseqüentemente contribuindo para a gênese do problema. A restrição do movimento normal dos músculos e articulações durante um período de rápido crescimento fetal resulta em fixação parcial de articulações, formação de ligamentos retraídos e mais curtos e de outros tecidos periarticulares, dando lugar às alterações clínicas da artrogripose [7,13,18]. Afirmou-se ainda que a etiopatogenia da artrogripose pode estar associada à degeneração de células nervosas presentes na haste anterior, durante os primeiros meses de gestação [10]. A artrogripose não parece ser uma alteração primária dos ossos ou articulações, mas sim da inervação dos músculos devido a disrafismo em nível de medula espinhal [20].

As informações de Riet-Correa et al. [18] de que a artrogripose cárpica pode apresentar-se acompanhada de falta de desenvolvimento e redução do tamanho das fibras musculares, com ocupação do espaço entre as fibras por tecido conjuntivo, sem contudo mencionar a presença de reação inflamatória local, justificam em parte, os achados clínicos observados nos animais deste estudo. Hidrocefalia, palatosquise, escoliose e disrafia espinhal são sinais clínicos freqüentemente encontrados em animais que apresentam quadros de artrogripose cárpica congênita [5,8,11]. Porém, não foram observadas no presente estudo.

Os resultados obtidos na comparação entre as frequiências da enfermidade em rebanhos de aptidão leiteira/mista e de corte foram coerentes com os indícios de que as raças de corte sejam as mais afeta- 
das pela enfermidade, especialmente a Charolesa, Hereford e Simental [13].

Dependendo das alterações associadas aos animais que apresentaram artrogripose, a condição pode ser letal. Entretanto, os casos levemente afetados recuperam-se completamente [6]. Esta afirmação confirma os achados dos bovinos do GI.

A maior ocorrência da enfermidade em animais do sexo masculino corroborou com os resultados encontrados por Lloyd [13], o qual afirmou que animais do sexo masculino são mais afetados pelo problema em relação aos do sexo feminino, mesmo não se observando diferença estatística sobre a ocorrência de artrogripose cárpica entre os sexos.

A cirurgia precoce é recomendada para restabelecer os movimentos de flexão da articulação cárpica, apesar da capacidade de movimentação permanecer limitada [6,14]. Esta condição foi observada nesse estudo, uma vez constatada a limitação dos movimentos articulares da região cárpica após a intervenção cirúrgica.

Analisando-se a comparação entre a evolução clínica dos animais operados do GI e do GII, infere-se que a recuperação dos casos levemente afetados pode estar associada ao grau de comprometimento da articulação e não ao método auxiliar de fixação externa.

As complicações ocorridas em um bovino do GIII e dois do GII podem estar diretamente associadas às condições de higiene, geralmente precárias nos locais onde os animais foram submetidos aos procedimentos cirúrgicos, podendo ter comprometido o controle das infecções tanto no trans como no pós-operatório. Considerando que a fixação com tubo de PVC apresenta características bastante semelhantes ao molde de gesso, em relação a estabilidade e tensão empregada na articulação do membro acometido com artrogripose cárpica, o comprometimento circulatório no membro do animal provocado pelo tubo, pode ser uma possível explicação para a presença de necrose da extremidade do membro, verificada em um animal pertencente ao GIII. Ao comparar o aparelho de Thomas com moldes de gesso na fixação externa de fraturas, constatou-se que o aparelho de Thomas, ao contrário do gesso, não resultou em alterações circulatórias [16].

Os resultados da comparação entre os métodos de fixação externa do GII e do GIII justificam o emprego dos tratamentos, sendo estes realizados em tempo hábil para que os movimentos de flexão da articulação fossem, no mínimo, parciamente restabelecidos [6,14].

\section{CONCLUSÃO}

Os tratamentos instituídos não resultaram na cura total de todos os bovinos, porém permitiu que os animais apoiassem a extremidade do membro ao solo e se locomovessem, mesmo claudicando, não havendo diferença quanto a recuperação dos bovinos levemente e gravemente afetados e entre os tratamentos, utilizando-se a Muleta de Thomas modificada e o Tubo de Policloreto de Vinila (PVC).

\section{NOTAS INFORMATIVAS}

${ }^{1}$ Rompun - BAYER do Brasil - São Paulo/SP.

${ }^{2}$ Biocid - PFIZER QUIMICA LTDA - São Paulo/SP.

${ }^{3}$ Anestésico L - PEARSON SAUDE ANIMAL LTDA - São

Paulo/SP.

${ }^{4}$ Septipen - VALLÉE S/A - São Paulo/SP.

${ }^{5}$ Ganadol - FORT DODGE SAUDE ANIMAL LTDA - Campinas/SP

\section{REFERÊNCIAS}

1 Agerholm J.S., Basse A. \& Christensen K. 1993. Investigations on the occurrence of hereditary diseases in the Danish cattle population 1989-1991. Acta Veterinaria Scandinavica. 34: 245-253.

2 Agerholm J.S., Bendixen C., Anderson O. \& Arnbjerg J. 2001. Complex vertebral malformation in Holstein calves. Journal of Veterinary Diagnostic Investigation. 13: 283-289.

3 Curi P.R. 1997. Metodologia e análise da pesquisa em ciências biológicas. Botucatu: Tipomic, 256p.

4 Dirksen G. 1993. Sistema locomotor. In: Dirksen G., Gründer H-D. \& Stöber M. (Eds). Rosenberger: exame clínico dos bovinos. 3.ed. Rio de Janeiro: Guanabara Koogan, pp.315-340.

5 Duncan R.B., Carrig C.B., Agerholm J.S. \& Benixen B. 2001. Complex vertebral malformation in a Holstein calf: report of a case in the USA. Journal of Veterinary Diagnostic Investigation. 13: 333-336.

6 Fraser C.M. 1991. Manual Merck de Veterinária, um manual de diagnóstico, tratamento, prevenção e controle de doenças para o veterinário. 6.ed. São Paulo: Roca, 1803p. 
Silva L.A.F., Franco L.G., Eurides D., Silva O.C., Silva M.A.M., Damasceno A.D., Alves R.O., Moura M.I., Garcia A.M. \& Trindade B.R. 2005. Aspectos clínicos, ocorrência e tratamento da artrogripose cárpica... Acta Scientiae Veterinariae. 33: 131-137.

7 Getty R. 1986. Osteologia geral. In: Anatomia dos Animais Domésticos. 5ed. Rio de Janeiro: Guanabara Koogan, pp.19-31.

8 Jagoe S., Kirkland P.D. \& Harpper P.A. 1993. An outbreak of Akabane virus-induced abnormalities in calves after agistment in an endemic region. Australian Veterinary Journal. 70: 56-58.

9 Jeong W.I., Lee C.S., Chung J.Y., Park S.J., An M.Y., Jeong D.H., Do S.H., Noh D.H., Williams B.H. \& Jeong K.S. 2003. Fetal bladder outlet obstruction in a stillborn bovine fetus. Journal of Veterinary Medicine Science. 65: $393-395$.

10 Jones T.C., Hunt R.D. \& King N.W. 2000. Patologia veterinária. 6.ed. São Paulo: Manole, 1415p.

11 Kitano Y., Yamashita S. \& Makinoda K.A. 1994. Congenital abnormality of calves, suggestive of a new type of arthropodborne virus infection. Journal of Comparative Pathology. 111: 427-437.

12 Leipold H.W., Hirarga T. \& Dennis S.M. 1993. Congenital defects of the bovine musculoskeletal system and joints. Veterinary Clinics of North America: Food and Animal Practice. 9: 93-104.

13 Lloyd K.C.K. 1994. Artrogripose. In: Smith P.B. (Ed). Tratado de medicina interna de grandes animais. São Paulo: Manole, $1738 \mathrm{p}$.

14 Lompa P.A. 2002. Artrogripose. Medicinal - Temas Saúde. Disponível em: <http://www.medicinal.com.br/temas/temas.asp? tema $=63>$ Acesso em: 30 de setembro de 2004 .

15 Longeri M.L., Perrone T., Bongioni G., Bona M., Zanotti M. \& Galli A. 2003. Survival motor neuron (SMN) polymorphism in relation to congenital artrogryposis in two Piedmont calves (piemontese). Genetics Selection Evolution. 35 (Suppl 1): 167-175.

16 Matera E. \& Stopiglia A.V. 1958. Tratamento cirúrgico das fraturas nos pequenos animais. Boletim da Sociedade Paulista de Medicina Veterinária. São Paulo. 11: 123-150.

17 Miranda A.H., Silva L.A.F., Garcia D.P., Oliveira K.S., Trindade B.R., Menezes L.B., Silva E.B. \& Silva O.C. 2003. Alterações estruturais e no tipo de imobilização dos membros locomotores de cães (Canis familiaris) utilizando o aparelho de Thomas modificado. MEDVEP - Revista Cientifica de Medicina Veterinária de Pequenos Animais e Animais de Estimação. 1: 185-190.

18 Riet-Correa F., Schild L.A. \& Méndez C.M. 1998. Doenças de Ruminantes e Eqüinos. Pelotas: Editora Universitária/ UFPel, 651p.

19 Stashak T.S. 1994. Claudicação em eqüinos segundo Adams. 4.ed. São Paulo: Roca, 942p.

20 Thomson R.G. 1983. Patologia Geral Veterinária. Rio de Janeiro: Guanabara Koogan, 412 p.

21 Uchida K., Murakami T., Sueyoshi M., Tsuda T., Inai K., Acorda J.A., Yamaguchi R. \& Tateyama S. 2000. Detection of Akabane viral antigens in spontaneous lymphohistiocytic encephalomyelitis in cattle. Journal of Veterinary Diagnostic Investigation. 12: 518-524. 